\title{
EXPRESSION PATTERNS OF PHOSPHATE TRANSPORTER GENE EcgPT ASSOCIATED WITH THE SALT STRESS RESPONSE IN PERENNIAL EUCALYPT TREE HYBRID CLONES
}

\author{
Eny Faridah ${ }^{1}$ \\ Received : 13 August 2012, Accepted : 9 December 2013
}

\begin{abstract}
Salinity effects on plant can often be related to mineral ion content alteration, including phosphate. Under saline conditions, phosphate levels were reported to decrease in plants. Such effects could indirectly affect intracellular phosphate levels, leading to phosphate deficiency, which in turn leads to increased activities of phosphate uptake mechanisms. This research was aimed to investigate the effects of salinity on the expression changes of phosphate transporter genes isolated from E. camaldulensis $\mathrm{x}$ E. globulus hybrid clones subjected to salt concentrations of 0 (control), 50, 100, and $150 \mathrm{mMNaCl}$. Fragments of genes (1164bp long and encodes 304 amino acid polypeptides) known to be involved in phosphate uptake were identified and isolated by RACE from these hybrids, encoding a Phosphate Transporter (EcgPT). Expression studies using Northern-Blot analysis revealed that the expression of EcgPT was found to be affected by salt, suggesting a direct effect of salinity on phosphate uptake. EcgPT was expressed differently in different clones, indicating different degrees of phosphate transporter activation in order to tolerate salt stress. Molecular data are discussed in relation to measurements of ion levels in different organs of different clones and under various salt regimes during the course of the hydroponic experiment.
\end{abstract}

Keywords: Phosphate transporter gene, salinity stress, phosphate content, eucalypt

\section{INTRODUCTION}

Plants have developed a variety of mechanisms to survive environmental stress. A dualmechanism model for ion uptake, including phosphate, has been proposed for many plants (Chrispeels et al., 1999; Epstein, 1966). This is characterized by a low-affinity uptake system operating at high $(\mathrm{mM})$ concentrations, and a high-affinity system functioning at low (M) concentration of ions. A high-affinity inorganic phosphate transporter (PT) was first recognized in Saccharomyces cerevisiae as the PH084 gene (BunYa et al., 1991). Later, several high-affinity Phosphate transporters have been identified and isolated in Arabidopsis, all belonging to the same gene family, Pht1 (Muchhal et al., 1996; Smith et al., 1997). Homologues to PT gene family have also

${ }^{1}$ Faculty of Forestry, Gadjah Mada University, Yogyakarta, Indonesia

*Corresponding Author: enyfaridah@ugm.ac.id been isolated from potato (Leggewie et al., 1997), tomato (Daram et al., 1998; Liu et al., 1998), and barley (Rae et al., 2003). The sizes of PT mRNAs differ in different species, but lengths of their Open Reading Frames (ORF) are similar. This high similarity of ORF among various plants indicates similar function of PT gene in those plant species, while the various lengths of untranslated regions in different species might reflect the host plant specific differences in PT gene function (Lam and Maisel, 1999).

High-affinity phosphate uptake system in all plants respond to phosphate deprivation with a dramatic increase in transcript levels (Schachtman et al., 1998). Transcriptional regulation of PTgenes primarily responded to the $\mathrm{P}$ status of the whole plant, and its protein level was reversible upon resupply of Pi (Liu et al., 1998; Muchhal and Raghothama, 1999).

Salinity is believed to disrupt the mechanisms that control intracellular orthophosphate (Pi) 
concentrations (Ashraf and Ahmad, 2000), and mechanism of general transporter activities (Chen et al., 2012). Such effects could indirectly regulate intracellular $\mathrm{P}$ levels, and lead to phosphate deficiency. This led to the hypothesis that phosphate deficiency might be a secondary effect of salinity (Plaxton and Carswell, 1999), and that salt-stressed plants may actively regulate their $\mathrm{P}$ uptake and transport systems to maintain uptake and distribution of $\mathrm{P}$.

Some eucalypt species are known for their tolerance to salt, but little is understood on how salt stress might affect nutrient uptake mechanism such as phosphate transporter. Therefore, the study aimed to investigate whether EcgPT (Eucalyptus camaldulensis $\mathrm{x}$ globulus Phosphate Transporter) expression is 1) regulated by salt, indicating an effect of salt stress on P uptake, and 2) differentially regulated in different clones, indicating various salt tolerance mechanisms.

\section{METHODOLOGY}

\section{A. Plant Material and Growing Conditions}

Six-month-old E. camaldulensis x E. globulus hybrid cuttings purchased from Saltgrow Company (from 9 clones coded as clones 1-9) were grown in hydroponic tubs in the glasshouse at a temperature of $21^{\circ} \mathrm{C} / 18^{\circ} \mathrm{C}$, under $14 \mathrm{~h} /$ day and $10 \mathrm{~h} /$ night regime. After growing in halfstrength nutrient solution for the first week the plants were transferred to full strength nutrient solution (Morris, 1984). In the third week, salt in the form of $\mathrm{NaCl}$ was added to the full-strength nutrient solution to final concentrations of $0 \mathrm{mM}$ (as control), $50 \mathrm{mM}, 100 \mathrm{mM}$, and $150 \mathrm{mM}$. Nutrient and salt solutions were renewed with fresh solution every week for the five-week duration of the experiment, and plants were harvested every week from different clones and different salt concentrations.

Upon harvesting, plants were divided into 3 parts: leaves, stems, branches, and roots. Some young leaves and parts of the root material were taken for nutrient analysis. The remaining samples (leaves, stems, roots) were separated into $50 \mathrm{~mL}$
Falcon tubes, immediately snap-frozen in liquid nitrogen and stored at $-80^{\circ} \mathrm{C}$ for total $\mathrm{RNA}$ extraction.

\section{B. 5' and 3' RACE (Rapid Amplification of cDNA Ends)}

Messenger RNA (mRNA) used for RACE was isolated from total RNA using a Promega mRNA isolation kit. The synthesized single stranded cDNA reactions produced were used as templates for amplification of $5^{\prime}$ and $3^{\prime}$ ends using the Clontech SMART TM RACE cDNA Amplification Kit.

To amplify PT cDNA fragments, two GC-rich Gene Specific Primers (PF1: CTCGTTACACCGCCC-TAGTGGCCAAGA and PR1: AGCGACCGTGAACCAGTATCCAGGGAC) were designed based on the sequence of previously amplified PT DNA PCR products (data not shown) to amplify the gene's 5' and 3 ' ends through RT-PCR. RACE reactions were carried out using Taq polymerase (Fermentas) and the following cycle profile: initial denaturation of cDNA at $95^{\circ} \mathrm{C}$ for $20 \mathrm{sec}, 35-38$ cycles of amplification by denaturing at $95^{\circ} \mathrm{C}$ for $5 \mathrm{sec}$, annealing at $60^{\circ} \mathrm{C}$ for $1 \mathrm{~min}$ and extending at $70^{\circ} \mathrm{C}$ for $2 \mathrm{~min}$, and a final extension at $70^{\circ} \mathrm{C}$ for $4 \mathrm{~min}$.

\section{Sequencing and Sequence Analysis}

Sub-cloned cDNAs were labeled using the CEQ 2000 Dye Terminator Cycle Sequencing Kit using T3 (5'-AATTAACCCTCACTAAAGGG3') or T7 (5'-GTAATACGACTCACTATAGGGC-3') primers. Sequences were determined using a CEQ8000 DNA Sequencer (Beckman Coulter). Sequences were compared with existing publicly available sequences using BLAST (http://www.ncbi.nlm.nih.gov). Sequence alignment and analysis were performed through facilities available at Bionavigator (http://www.bionavigator.com), and the Expasy Molecular Biology (http://kr.expasy.org), as well as additional sequence analysis such as PSORT analyses.

\section{d. Northern Blot Analysis}

Analysis was conducted as prescribed by 
Amersham pharmacia in 2004. Probes designed to 3 ' end used for Northern Blotting was EcgPT DNA fragments (data not shown). Amounts of RNA loaded onto each gel were visualized and compared using Ethidium Bromide (EtBr) staining. DNA probes were radioactively labeled using the Decalabel ${ }^{\mathrm{TM}}$ DNA labeling kit (Fermentas) and $\left[\alpha^{32} \mathrm{P}\right]$-dATP (Perkin Elmer). Labeling, prehybridization and hybridization methods were done following manufacturer's instructions.

\section{RESULT AND DISCUSSION}

\section{a. EcgPTRace}

The cloned EcgPT (EcgPT-3') was 1096bp in length, and combination with a 68bp sequence from the genomic PT DNA fragment (located 5' direction) resulted in a 1164bp sequence encoding a 305 amino acid polypeptide. This fragment contained a 3'-untranslated region of $249 \mathrm{bp}$ length. Alignment to other PTs at the deduced amino acid level confirmed the end of the coding region and the position of $E c g P T$ in relation to other PTs (Figure 1).

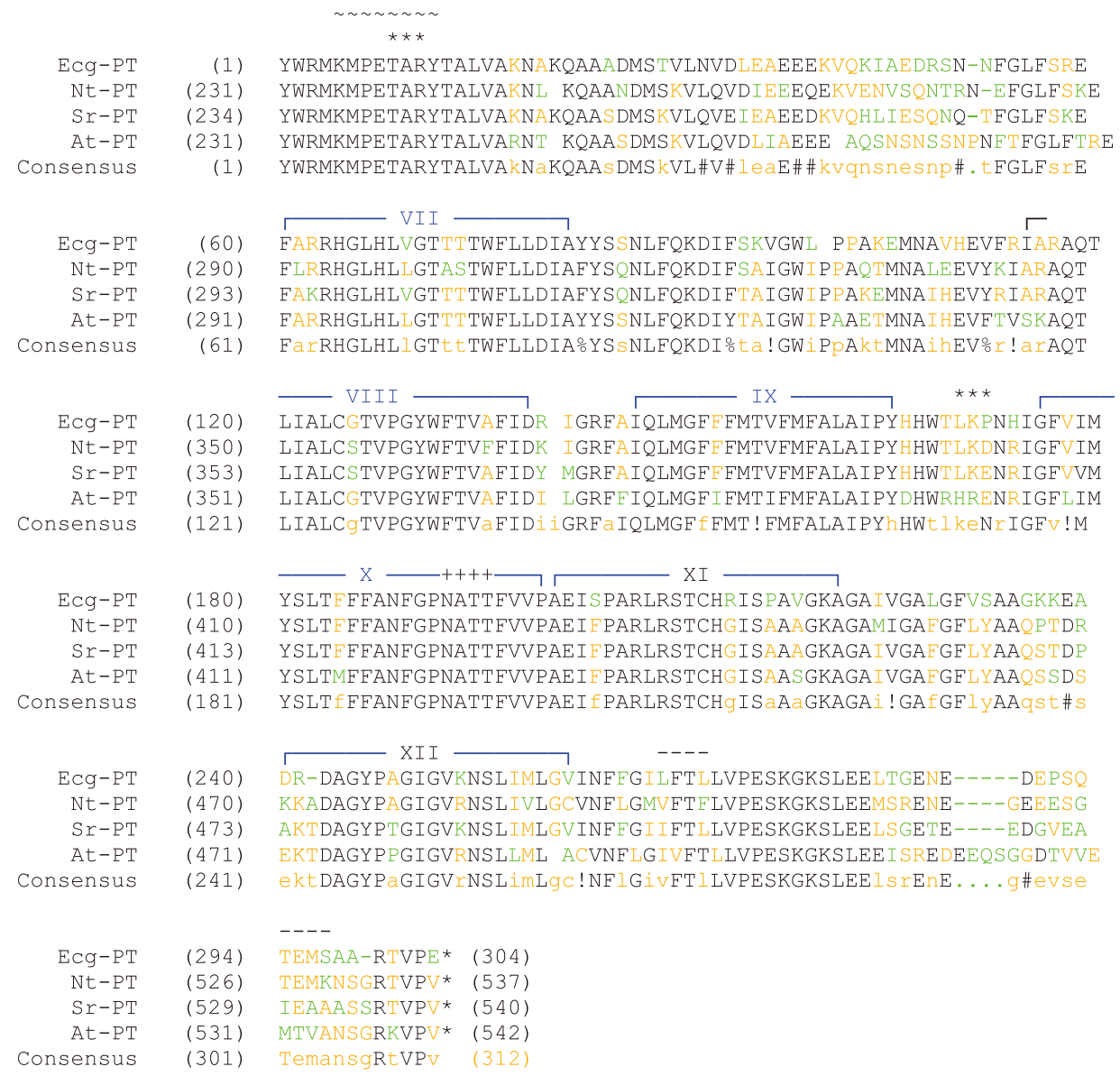

Figure 1. Deduced amino acid alignment of EcgPT and three known PTs: Nicotiana tabacum (NtPT, acc. no: AAF74025), Sesbania rostrata (SrPT, acc. no: CAC28219), and Arabidopsis thaliana (AtPT, acc. no: BAA24280). Amino acids conserved among all four clones (full consensus) are shown in black, upper-case letters; medium consensus (those conserved among three or two clones) are represented by orange, lower-case letters. Other consensus symbols are: ! (I and V), \$ (L and $\mathrm{M}), \%(\mathrm{~F}$ and $\mathrm{Y})$, and $\#(\mathrm{~N}, \mathrm{D}, \mathrm{Q}, \mathrm{E}, \mathrm{B}$, and $\mathrm{Z})$. Asterisks indicate the stop codon. Possible transmembrane domains are indicated by Roman numerals (generated based on hydropathy analysis (http://saier-144-37.ucsd.edu) and PT gene structure in tomato (Daram et al. 1998) and Arabidopsis(Muchhal et al. 1996)). Consensus sites for phosphorylation by protein kinase C (***), site for phosphorylation by casein kinase II (----), site for N-glycosylation $(+++)$, and site for tyrosine phosphorylation $(\sim \sim \sim \sim \sim)$ are also shown. 
Table 1. Nucleotide and amino acid sequence identity ${ }^{*}$ between available Pts

\begin{tabular}{lllllll}
\hline & Ecg-PT & Sr-PT & Nt-PT & At-PT & St-PT & Os-PT \\
\hline Ecg-PT & --- & $80.8(88.3)$ & $76.1(86.4)$ & $71.9(82.7)$ & $70.1(79.4)$ & $68.5(80.5)$ \\
Sr-PT & 73.1 & --- & $80.1(89.3)$ & $76.9(86.2)$ & $76.5(84.7)$ & $74.6(84.0)$ \\
Nt-PT & 69.1 & 71.3 & --- & $74.8(86.0)$ & $76.5(85.7)$ & $74.0(84.1)$ \\
At-PT & 67.7 & 68.3 & 68.0 & --- & $67.9(79.2)$ & $66.0(77.3)$ \\
St-PT & 67.6 & 69.7 & 70.1 & 65.8 & --- & $68.5(80.1)$ \\
Os-PT & 67.8 & 65.8 & 62.7 & 66.3 & 61.2 & --- \\
\hline
\end{tabular}

left-hand side of the diagonal matrix $=$ nucleotide identity, right-hand side of the diagonal matrix $=$ amino acid identity $($ similarity shown in brackets)

${ }^{* *}$ Percentages of identity and similarity shown were determined by alignment of two sequences at a time (www.ebi.ac.uk). Accession numbers of nucleotide and protein sequences of each clones are as follows:

Sr-PT (Sesbaniarostrata, nucleotides: AJ286744, protein: CAC28219),

Nt-PT (Nicotianatabacum, nucleotides: AF156696, protein AAF74025),

At-PT (Arabidopsis thaliana, nucleotides: NM_128843, protein: BAA24280),

St-PT (Solanumtuberosum, nucleotides: X98891, protein: CAA67396),

Os-PT (Oryza sativa, nucleotides: AF536968, protein: AAN39049).

Based on its deduced amino acid sequence, a PSORT analysis (Prediction of Protein Localization Sites, http://psort.nibb.ac.jp) predicted that EcgPT is likely to be localized in mitochondrial inner membranes (certainty= 0.746 ) or in the plasma membrane (certainty= 0.600). This result suggests that EcgPT encodes a transmembrane PT (refer to Figure 1). When the nucleotide sequence of the EcgPT fragment was aligned to cDNAs of potato and Arabidopsis thaliana PTs, it showed $67.6 \%$ and $67.7 \%$ identity, respectively. A summary of identity values among available PTs is shown in Table 1.

\section{b. EcgPT Expression Patterns in $E$. camaldulensis $\mathrm{x}$ E. globulus Hybrid Clones}

Effects of salinity on the expression of Phosphate transporter genes in E. camaldulensis $x$ E. globulus hybrids (EcgPT) were studied by subjecting various clones to different salt concentrations (0mM, 50mM, $100 \mathrm{mM}$, and $150 \mathrm{mM})$. When membranes containing total RNA were probed with EcgPT (DNA), $\pm 2.9 \mathrm{~kb}$ transcripts were detected (Figure 2). After two weeks of salt stress, EcgPT expressions in the leaves of clone 7 were not noticeable at 0 and $50 \mathrm{mM} \mathrm{NaCl}$, slightly increased at $100 \mathrm{mM} \mathrm{NaCl}$ and reached its peak at $150 \mathrm{mM} \mathrm{NaCl}$ concentration (Figure 2A). Similar patterns were noticed for stem tissues of clone 5 exposed to salt for three weeks (Figure 2B). In this clone, however, expression at salt levels $100 \mathrm{mM}$ and $150 \mathrm{mM}$ was higher than that found for leaves of clone 7 . The initial conclusion from these observations is that the expression of EcgPT is regulated by salt.

In order to examine whether EcgPT gene expression in various organs was affected differently by increasing salt concentrations, total RNA was isolated from roots, stems and leaves after plants were exposed to various salt levels. In clone 9 (Figure 3), EcgPT transcripts in leaves were clearly detectable under control conditions, and gradually increased with increasing salt levels, reaching a peak at $100 \mathrm{mM}$ salt level, but declined slightly at salt level. In roots, EcgPT transcripts were noticeable even without salt treatment. Expression slightly increased when plants were treated with $50 \mathrm{mM} \mathrm{NaCl}$. At $100 \mathrm{mM} \mathrm{NaCl}$ expression declined again, and remained constant at the highest salt level. EcgPT expression in stems was not noticeable in plants not subjected to salt treatment or at $50 \mathrm{mM} \mathrm{NaCl}$. Increasing salt concentration to $100 \mathrm{mM}$ slightly increased EcgPT transcript levels, but at $150 \mathrm{mM} \mathrm{NaCl}$ EcgPT expression could not be observed.

EcgPT was differentially expressed not only in plant organs, but significant differences also were observed between different clones. EcgPT transcripts as they were accumulated in leaves of all clones (clones 1-9) exposed to $150 \mathrm{mM} \mathrm{NaCl}$ for two weeks are shown in Figure 4A, illustrating different activity levels of EcgPT genes in different clones in response to the same salt stress levels. Accumulation of EcgPT transcripts could be related to the accumulation of $\mathrm{P}$ in leaves of the corresponding groups of clones (Figure 4B), i.e. 
A)

C7-L-W2

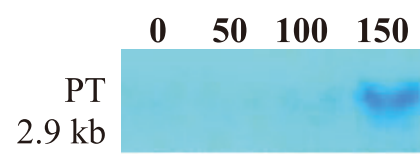

$2.9 \mathrm{~kb}$

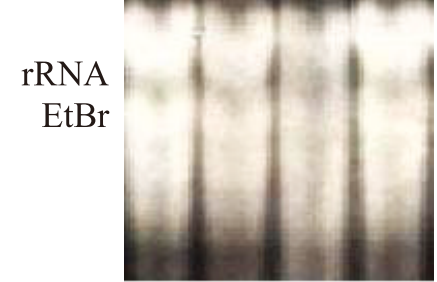

B)

C5-S-W3

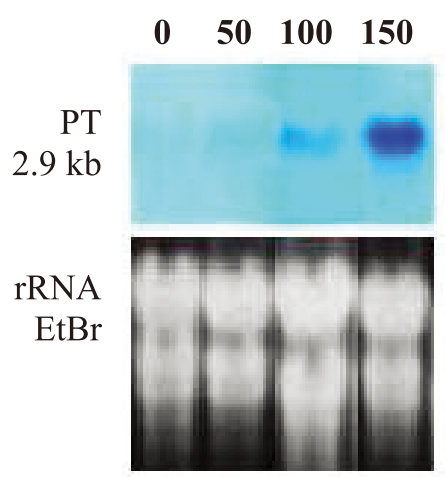

Figure 2. EcgPT expression in E. camaldulensis $\times$ E. globulus as induced by NaCl. A. Leaves (L) of clone 7 (C7) after two weeks (W2) of exposure, and B. Stems (S) of clone 5 (C5) after three weeks (W3) of exposure to $0 \mathrm{mM}, 50 \mathrm{mM}, 100 \mathrm{mM}$, and $150 \mathrm{mM} \mathrm{NaCl}$. Total RNA loaded in each lane was $20 \mu \mathrm{g}$.

\section{C9-W2}

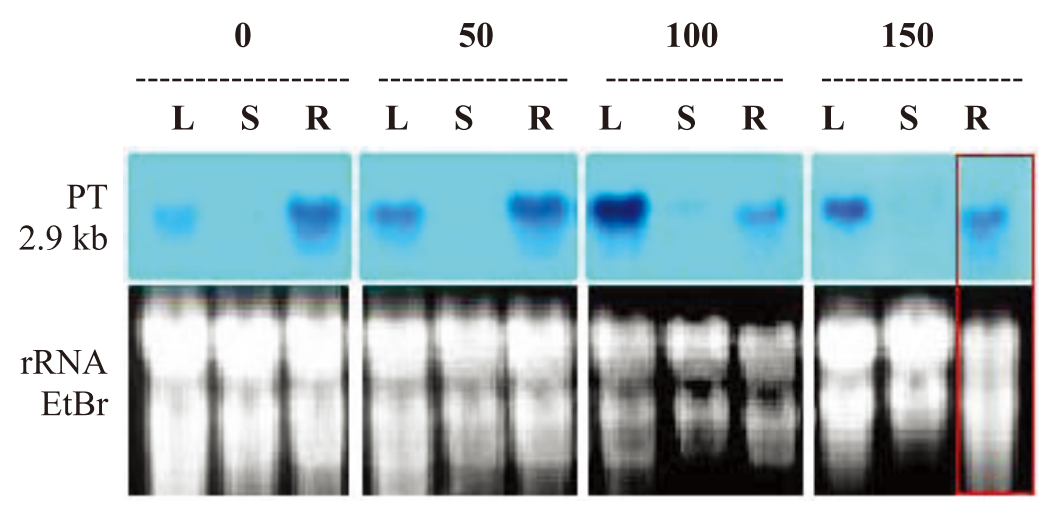

Figure 3. EcgPT expression in different plant organs $(\mathrm{L}=$ leaves, $\mathrm{S}=$ stems, $\mathrm{R}=$ roots $)$ of E. camaldulensis $x$ E. globulus clones. Clone 9 after two weeks of exposure (W2) to 0mM, 50mM, 100mM, and $150 \mathrm{mM} \mathrm{NaCl}$. Total RNA loaded for each sample was $20 \mu \mathrm{g}$. EtBr-staining confirmed that equal amounts were loaded in each lane. Boxed lanes are suspected to contain degraded RNA.

A

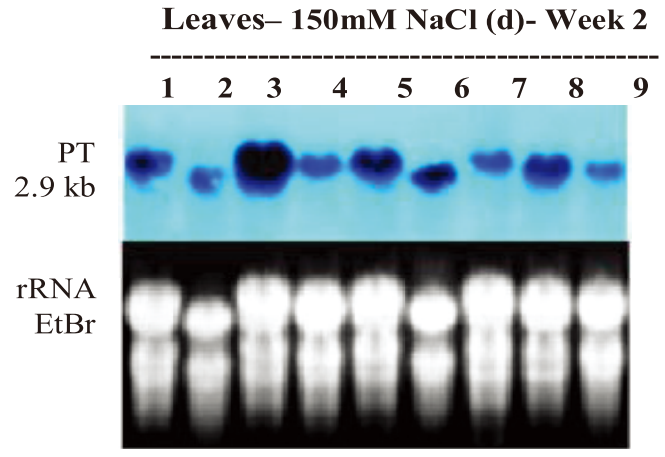

B

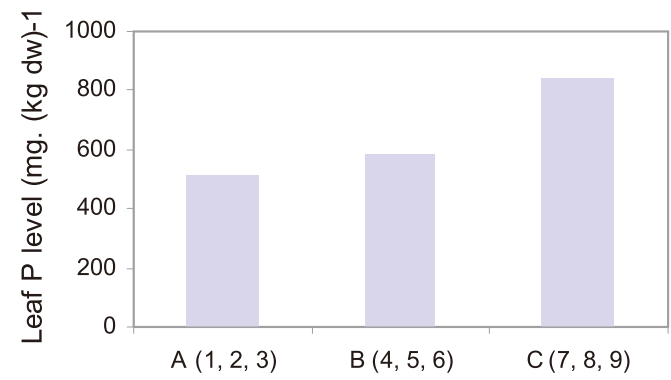

After two-week 150mM salt treatment

Figure 4. EcgPT expression and P levels in plant leaves. A) Expression in different E. camaldulensis $x$ E. globulusclones after different lengths of exposure to $150 \mathrm{mM} \mathrm{NaCl}$. Total RNA loaded in each lane was

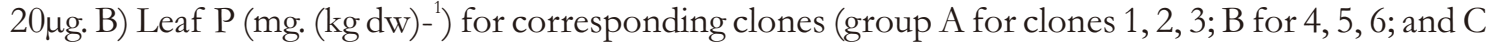
for $7,8,9)$. 
groups with lower leaf P content showed higher EcgPT expression levels.

\section{c. Amplification, Cloning and Sequence Analysis of $\operatorname{EcgPT}$}

A Phosphate Transporter (PT) cDNA from E. camaldulensis $\times$ E. globulus was amplified by RACE, and further characterized and used for gene expression studies. A composite cDNA was assembled from two overlapping clones, EcgPT-3', amplified by RACE, and EcgPT DNA, a cloned PCR product amplified from genomic DNA. The EcgPT is 1096bp long and encodes a 305 amino acid polypeptide. EcgPT also contains a 3'untranslated region of $249 \mathrm{bp}$ and a stop codon (TAA) located at the $913^{\text {th }}$ nucleotide (Figure 1). RACE and the subsequent cloning of PTs from E. camaldulensis $\times$ E. globulus only yielded a single EcgPT clone. However, it is common for some plant species to have several PTs, as is the case for Arabidopsis thaliana with AtPT1 and AtPT2 (Muchhal et al., 1996), or potato with StPT1 and StPT2 (Leggewie et al., 1997).

Alignment results showed high homology between EcgPT and high-affinity PTs from a diverse range of plant species, and indicated that the EcgPT gene fragment is not located towards the $5^{\prime}$ end of the gene-coding region when compared to other PTs (Figure 1). Being incomplete, EcgPT might not contain consensus sequences specific to other PT genes. As an example, EcgPT does not contain another site for phosphorylation by protein kinase, which is located around transmembrane domains IV. As expected, the localization of $\mathrm{E} c g P T$ was predicted by PSORT to be within the plasma membrane $($ certainty $=0.600)$, although PSORT also predicted it to be localized in mitochondrial inner membrane (certainty $=0.746$ ), Golgi body (certainty $=0.400)$, and chloroplast thylakoid membrane (certainty $=0.349$ ). These results underline the function of EcgPT as a transporter/symporter.

\section{d. Expression Studies of EcgPT}

$P$ deprivation leads to an increase in transcript levels of Phosphate transporters, as demonstrated in plants of Arabidopsis (Smith et al., 1997), tomato (Mutikara et al., 2001), potato (Leggewie et al., 1997), barley (Rae et al., 2003) and green algae
Dunaliellasalina (Li et al., 2012). In this study, exposure to $\mathrm{NaCl}$ increased the accumulation of EcgPT transcripts in E. camaldulensis $\mathrm{x}$ E. globulus, resembling symptoms of plants deprived of $\mathrm{P}$ (Figure 2). In fact, at higher salt concentrations, accumulation of EcgPT transcripts was observed to increase in all plant organs, indicating that increasing $\mathrm{NaCl}$ levels further reduced $\mathrm{P}$ uptake and hence $\mathrm{P}$ levels in plants. In addition, the expression of EcgPT in response to salt treatment differed in an organ-specific manner (Figure 3).

In plants grown without stress, EcgPT expression was noticeable in roots and leaves, but not in stems. These results are consistent with findings in potato, where StPT1, a high-affinity PT, was highly expressed in roots, source leaves and flower buds, but not in stems (Leggewie et al., 1997). This ubiquitous and relatively high base level of expression in leaves and roots might indicate that EcgPT has important physiological functions in E. camaldulensis x E. globulus even in the absence of stress. Roots are the organs involved in nutrient acquisition, and once roots take up phosphate, this will be transported in the xylem to the leaves, and hence expression patterns of EcgPT genes in roots and leaves correlated well with their physiological function.

$\mathrm{NaCl}$-induced EcgPT expression differed between clones (Figure 4A). Exposure to $150 \mathrm{mM}$ $\mathrm{NaCl}$ for two weeks increased EcgPT expression in leaves however, some exceptions were noted. Clones 2, 7 and 9 for example showed lower expression than other clones. When comparing different expression levels of EcgPT to accumulated $\mathrm{P}$ levels in corresponding clone groups (Figure 4B), it seems that despite relatively lower expression levels after longer exposure to stress, higher EcgPT expression levels initially might be associated with lower $P$ accumulation in leaves. For example, clones 7, 8, and 9 (Group C), whose leaf $\mathrm{P}$ levels were the highest on average showed the lowest EcgPT expression levels. Consistently, Group A showing the lowest P accumulation levels responded with higher EcgPT expression on average.

\section{CONCLUSION}

Although it is difficult to answer with certainty 
whether different EcgPT expression levels are in fact related to leaf P levels, and whether these are largely affected by salt stress, it can be concluded that EcgPT expression in E. camaldulensis $\mathrm{x} E$. globulus clone hybrids was regulated by salt levels in organ-specific manner and differently regulated in different clones. More research is needed to clearly establish the connection between EcgPT activation and plant physiological state (e.g. nutrient status) and to understand how EcgPT gene expression is influenced by environmental stresses.

\section{REFERENCES}

Ashraf, M., \& Ahmad, S. (2000). Influence of sodium chloride on ion accumulation, yield components and fibre characteristics in salt tolerant and salt-sensitive lines of cotton (Gossypium birsutum L.). Field Crops Research, 66(2), 115-127.

Bun-Ya, M., Nishimura, M., Harashima, S., \& Oshima, Y. (1991). The PHO84 gene of Saccharomyces cerevisiae encodes an inorganic phosphate transporter. Molecular and Cellular Biology, 11(6), 3229-3238.

Chen, S., Jiang, J., Li, H., \& Liu, G. (2012). The saltresponsive transcriptome of Populus simonii $\times$ Populus nigravia DGE. Gene, 504(2), 203-212.

Chrispeels, M. J., Crawford, N. M., \& Schroeder, J. I. (1999). Proteins for transport of water and mineral nutrients across the membranes of plant cells. Plant Cell, 11, 661-676.

Daram, P., Brunner, S., Persson, B. L., Amrhein, N., \& Bucher, M. (1998). Functional analysis and cellspecific expression of a phosphate trans porter from tomato. Planta, 206, 225-233.

Epstein, E. (1966). Dual pattern of ion absorption by plant cells and by plants. Nature, 212, 13241327.

Lam, E., \& Maisel, L. (1999). Gene switches and stress management: Modulation of gene expression by transcription factors. In H. R. Lerner (Ed.), Plant responses to environmental stresses: from phytohormones to genome reorganization (pp. 51-70). New York: Marcel Dekker, Inc.

Leggewie, G., Willmitzer, L., \& Riesmeier, J. W. (1997). Two cDNA from potato are able to complement a phosphate uptake deficient yeast mutant: identification of phosphate transporter from higher plants. Plant Cell, 9, 381-392.

Li, S. H., Xia, B. B., Zhang, C., Cao, J., \& Bai, L. H. (2012). Cloning and characterization of a phosphate transporter gene in Dunaliella salina. Basic Microbiol, 52, 429-436.

Liu, C., Muchhal, U. S., Uthappa, M., Kononowicz, A. K., \& Raghothama, K. G. (1998). Tomato phosphate transporter genes are differentially regulated in plant tissues by phosphorus. Plant Physiology, 116, 91-99.

Morris, J. D. (1984). Comparative salt tolerance of ornamental trees and shrubs for victorian field planting (Victoria Research Branch Report No. 249). Forest Commission: Victoria.

Muchhal, U. S., \& Raghothama, K. G. (1999). Transcriptional regulation of plant phosphate transporters. Proc. Natl. Acad. Sci. USA, 96, 5868-5872.

Muchhal, U. S., Pardo, J. M., \& Raghothama, K. G. (1996). Phosphate transporters from the higher plant Arabidopsis thaliana. Proc. Natl. Acad. Sci. US A, 93, 10519-10523.

Mutikara, U. T., Liu, C., Varadarajan, D. K., \& Ragothama, K. G. (2001). Negative regulation of phosphate starvation induces genes. Plant Physiology, 127, 1854-1862.

Plaxton, W. C., \& Carswell, M. C. (1999). Metabolic aspects of the phosphate star vation response in plants. In H. R. Lerner (Ed.), Plant responses to environmental stresses: from phytohormones to genome reorganization (pp. 349-372). New York: Marcel Dekker, Inc.

Rae, A. L., Cybinski, D. H., Jarmey, J. M., \& Smith, F. W. (2003). Characterization of two phosphate transposters from barley: evidence for diverse function and kinetic properties among members of the Pht1 family. lant Mol. Biol., 53, 27-36.

Schachtman, D. P., Reid, R. J., \& Ayling, S. M. (1998). Phosphorus uptake by plants: from soil to cell. Plant Physiolology, 116, 447-453.

Smith, F. W., Ealing, P. M., Dong, B., \& Delhaize, E. (1997). The cloning of two Arabidopsis genes belonging to a phosphate transporter family. The Plant Journal, 11(1), 83-92. 
